\title{
A revista Ciência Hoje das Crianças no letramento escolar: a retextualização de artigos de divulgação científica'
}

Sheila Alves de Almeida"

Marcelo Giordan"II

I- Esta pesquisa contou com o apoio da Fundação Ford e do CNPq.

II- Universidade Federal de Ouro Preto Ouro Preto, MG, Brasil.

Contato: sheilaalvez@iceb.ufop.br

III- Universidade de São Paulo, São Paulo, SP, Brasil.

Contato: giordan@usp.br

\section{Resumo}

Este trabalho trata da compreensão de como o discurso das crianças (re)produz artigos da revista Ciência Hoje das Crianças na sala de aula. Para tanto, foi analisado um episódio em que as crianças relatam textos lidos. A perspectiva teórico-metodológica de análise inspira-se nas concepções de Bakhtin acerca da interação verbal e na análise microgenética. Foram registradas cenas de trabalho em aulas de ciências com crianças na faixa etária entre 9 e 10 anos ( $4^{\circ}$ ano do Ensino Fundamental) de uma escola pública da rede municipal da cidade de Belo Horizonte. Observou-se que os discursos das crianças contêm aspectos da linguagem de divulgação científica e da oralidade. A forma de organização da aula em torno de uma revista de divulgação científica, em suporte original, resultou em retextualizações com evidências sobre a compreensão dos textos de divulgação científica, seja por suas características informativas, seja por sua natureza narrativa. Além disso, a análise da interação entre oralidade e escrita na atividade de relato de leitura evidenciou que as crianças utilizam os textos de divulgação científica ora como prática discursiva, ora como objeto, o que foi relacionado ao desenvolvimento da competência de metalinguagem. Nessa perspectiva, a retextualização constitui uma prática de letramento que possibilita a expressão de conhecimentos, a construção de ideias e a habilidade de uso de uma linguagem explicativa.

\section{Palavras-chave}

Aprendizagem - Discurso - Divulgação científica - Ensino fundamental - Relato de leitura. 


\title{
The magazine Ciência Hoje das Crianças in school literacy: the retextualization of popular science articles'
}

Sheila Alves de Almeida"

Marcelo Giordan"II

\begin{abstract}
This paper discusses how children's discourses in the classroom (re)produce articles of the magazine Ciência Hoje das Crianças. For this purpose, we analyzed an episode in which the children reported on the texts they had read at home. Microgenetic analysis and Bakthin's concepts regarding verbal interaction inspired the theoretical and methodological perspective of analysis. We recorded the work in science classes with children aged 9 to 10 years (4th grade of primary education), in a public school of Belo Horizonte city, Minas Gerais state. We observed that children's discourses contain some aspects of the language of science popularization and of orality. Organizing the class according to the science popularization magazine, in its original support, resulted in retextualizations with evidence of the understanding of the popular science texts, whether for their informative characteristics or for their narrative nature. Furthermore, the analysis of the interaction between orality and writing in the reading reports evidenced that children use science popularization texts both as a discursive practice and as an object, which was related to the development of the metalanguage competence. In this view, retextualization is a literacy practice that allows expressing knowledge, constructing ideas and the ability to use explanatory language.
\end{abstract}

\section{Keywords}

Learning - Discourse - Science popularization - Primary education - Reading report.

\footnotetext{
I- This research was supported by Ford Foundation and CNPq.

II- Universidade Federal de Ouro Preto, Ouro Preto, MG, Brasil.

Contact: sheilaalvez@iceb.ufop.br

III- Universidade de São Paulo, São Paulo, SP, Brasil. Contact: giordan@usp.br
} 
As interações do leitor com o texto têm sido objeto de preocupação crescente de muitas pesquisas no campo da educação em ciências (ALMEIDA; GIORDAN, 2012; ALMEIDA, 2010; ESPINOZA, 2010; ESPINOZA; CASAMAJOR; PITTON, 2009). No entanto, a maior parte da produção nessa área está concentrada nas últimas séries do Ensino Fundamental. As relações entre leitura, linguagem e ensino nas aulas de ciências nas séries iniciais têm sido pouco estudadas. Talvez a preocupação desse segmento com a alfabetização da língua materna - no sentido estrito desse termo - e a ausência de práticas significativas em educação em ciências nos primeiros anos justifiquem tal lacuna. Prova disso é que as crianças não guardam lembranças significativas das leituras realizadas nas aulas de ciências (ALMEIDA, 2005; ESPINOZA; CASAMAJOR; PITTON, 2009). A maioria dos alunos não se lembra dos livros e das imagens, não tem memória do prazer e da curiosidade que um mergulho em um texto de ciências pode proporcionar (ALMEIDA, 2005).

Em seus estudos, Silva (1999) denomina como reducionistas as concepções que consideram a leitura um simples ato de oralização de um texto, decifração de um código ou expressão de uma ideia fixa contida no texto. Em suas investigações, o autor enfatiza a importância de uma concepção interacionista da leitura. Nessa direção, Kleiman (2004, p. 10) argumenta que a aprendizagem da leitura é um processo que acontece na interação, isto é, "na prática comunicativa em pequenos grupos" - seja com o professor, seja com seus pares -, bem como na promoção de um contexto adequado para que a criança que não entendeu a leitura possa compreendê-la. Também compartilham de tal concepção Zilberman (1982), Marinho (1993), Soares (1998), Marcuschi (2001b), Geraldi (2002), Solé (2003), Rojo (2004), Colello (2004) e Goulart (2006).

Nessa mesma vertente, na área de educação em ciências, a leitura e a escrita têm se destacado nas pesquisas como aspectos importantes para o desenvolvimento do letramento. Dentre os pesquisadores que sustentam essa ideia, estão: Sutton (2003), Cassiani (2006), Zimmermann e Silva (2007), Almeida (2010), Mortimer, Vieira e Araújo (2010), Espinoza (2010) e Paula e Lima (2011).

Para Espinoza, Casamajor e Pitton (2009), um texto informativo no campo das ciências se apresenta como uma possibilidade de conhecer algumas características do trabalho e do discurso científico. De acordo com Espinoza (2010), nas aulas de ciências, normalmente não se pensa em situações de leitura como cenários de ensino e aprendizagem envolvendo, simultaneamente, conhecimentos da área e também de leitura, de modo geral. As situações propostas costumam partir do princípio de que os alunos já sabem ler e de que isso é suficiente para a interpretação do texto.

Massarani (2007) considera que os textos de divulgação científica para crianças são instrumentos úteis para a educação formal. Em sua opinião, é importante que as crianças tenham acesso à discussão de temas atuais e polêmicos. Por sua vez, a tese de doutorado de Gouvêa (2000) constitui uma iniciativa importante para a compreensão de como se processa a leitura de textos de divulgação científica veiculados na revista Ciência Hoje das Crianças (CHC) e de como a leitura desse tipo de texto aproxima esse público da linguagem científica. Em sua investigação, o estudo das práticas de leitura foi realizado mediante entrevistas com crianças que liam regularmente a revista em suas casas e eram assinantes do periódico. Uma das indicações apontadas pela autora é de que a maioria das crianças pode não entender todos os conceitos expostos, mas acompanha a linha de exposição do texto.

Embora esses trabalhos ressaltem a importância do discurso de divulgação científica para as crianças, nenhum deles se debruçou sobre o aspecto que aqui nos interessa: Como o discurso de divulgação científica é (re)produzido pelas crianças no contexto da sala de aula? Quais aspectos do discurso de divulgação científica são apropriados pelas crianças na leitura dos artigos da revista CHC nas aulas de ciências? 
A partir da investigação dessas questões, foi possível perceber que a leitura da revista CHC dentro de sala de aula não apenas revela os vínculos desse material com o ensino mas também contribui para uma revisão de conceitos-chave para os estudos da oralidade nas aulas de ciências.

Em seus trabalhos, Goulart (2006) reafirma que o letramento afeta o pensamento por intermédio do desenvolvimento de meios de se falar sobre o texto. Destaca, ainda, a importância de práticas de ensino: que trabalhem com as crianças diferentes linguagens sociais em que a inter-relação de gêneros primários e secundários do discurso seja vivenciada; que envolvam situações em que a linguagem escrita seja a fonte das interações, constituindo-se em eventos de letramento; que promovam reflexão sobre a própria linguagem, no sentido do desenvolvimento de uma metalinguagem.

$\mathrm{Na}$ sala de aula em que foi realizado o trabalho de pesquisa Interações e práticas de letramento mediadas pela revista Ciência Hoje das Crianças (ALMEIDA, 2011), a ação de leitura era sempre acompanhada por um convite de dizer a leitura. Tal momento, caracterizado como relatos de leitura, consistia em redizer os artigos. Assim, a leitura retornava transformada. Nesse processo, eram produzidos textos orais erigidos em uma rede de alusões e citações, numa espécie de discurso bricoleur, feito de pedaços essencialmente dialógicos, estrategicamente metabolizados e colados na urdidura textual do aluno-leitor. Com base nessa investigação, o presente trabalho apresenta uma experiência em que a linguagem de divulgação científica para crianças aparece em uso e aponta um caminho importante para a análise das relações entre oralidade e escrita nas aulas mediadas pela revista Ciência Hoje das Crianças.

\section{Pressupostos teóricos}

Enfocamos aqui dois aspectos gerais que nos interessam para analisar as situações de leitura e discussão de textos da revista CHC em sala de aula. 0 primeiro diz respeito ao conceito de gêneros do discurso e o segundo refere-se ao conceito de letramento escolar e oralidade.

De acordo com Bakhtin (1997), a enunciação é produto da relação social e qualquer enunciado fará parte de um gênero. Por estarem inseridos em diversas esferas sociais, os gêneros não são completamente estáveis, mas estão em contínua transformação no mesmo instante em que buscam garantir certa estabilização. Nessa perspectiva, os gêneros são duplamente determinados: pelos sentidos do discurso e pelas formas, pelos significados e pelas construções de um gênero específico. Para classificar determinado enunciado como pertencente a dado gênero, é necessário que verifıquemos suas condições de produção, circulação e recepção.

Em meio à grande diversidade de gêneros do discurso - literários, científicos, cotidianos, retóricos, políticos, artísticos, jurídicos etc. -, Bakhtin (1997) sugere uma categorização em termos de gêneros primários e secundários. A divisão se dá de acordo com o grau de complexidade e de evolução das formas de comunicação do grupo social. Durante a formação dos gêneros secundários, os gêneros primários são assimilados e transformados, perdendo sua relação imediata com a realidade existente $\mathrm{e}$ com a realidade dos enunciados alheios. Bakhtin parece admitir uma espécie de recontextualização dos gêneros primários durante esse processo, pois, ao sugerir a perda de vínculo imediato com a realidade, considera que esses tipos enunciativos são transferidos para outros contextos, para outras esferas da realidade.

Bunzen (2009) compreende a escola como uma esfera de comunicação que possibilita a produção, a utilização e a recepção de determinados gêneros do discurso nas variadas atividades de linguagem. Nessa perspectiva, a escola é um lugar de produção de textos por sujeitos que possuem papéis sociais e funções a ela relacionadas. A noção de esfera traz em seu bojo a relação entre situação de comunicação e gêneros do discurso. Para Bunzen (2009), a escola é, ao mesmo tempo, um lugar de recepção dos 
textos sociais e de interpretação e apropriação desses discursos. Como consequência de tal posicionamento, a expressão letramento escolar é utilizada pelo autor como um conjunto de práticas discursivas que envolvem os usos da escrita da/na esfera escolar.

Marcuschi (2001b) afirma que o termo letramento está semanticamente saturado. Segundo ele, esse termo significou coisas diversas ao longo da história e também em uma mesma época. Em seus estudos, o autor defende que é impossível investigar questões relativas às práticas da leitura e da escrita sem uma abordagem etnograficamente situada e uma inserção cultural das questões no domínio cognitivo. Ainda segundo Marcuschi (2001b), investigar o letramento é observar práticas linguísticas em situações em que tanto a escrita quanto a fala são centrais para as atividades em curso. De acordo com esse autor, o conceito de letramento se institui e se constitui na interface com a oralidade. Assim, tanto o discurso falado quanto o discurso escrito dispõem do mesmo sistema linguístico para organizar seus enunciados, sendo mobilizados de acordo com os eventos sociais comunicativos. Nessa interação entre a oralidade e a escrita, Marcuschi (2001a) chama de retextualização o processo que envolve a passagem do texto falado para o escrito e vice-versa. Para ele, o processo de retextualização não consiste, simplesmente, em repetir o texto-fonte. Trata-se de produzir um discurso, isto é, dizer de outro modo, em outra modalidade ou em outro gênero, o que foi dito ou escrito por alguém.

Segundo Marcuschi, há, nas atividades de retextualização, um aspecto muito importante: a compreensão. Para Bakhtin (1997), a compreensão envolve a busca de contrapalavras em resposta às palavras do outro. 0 locutor produz o enunciado aguardando uma resposta de seu interlocutor, na forma de concordância, objeção, execução ou outra atitude responsiva, e isso se dá em razão de ele ter em mente a existência de enunciados anteriores aos quais seu enunciado responde. A compreensão é, portanto, uma forma de diálogo que se estabelece pela oposição e pela recontextualização de palavras. Nesse sentido, qualquer compreensão verdadeira é dialógica por natureza. Em uma perspectiva confluente entre Marcuschi e Bakhtin, a retextualização envolve construção de sentido e trabalho de compreensão.

Kleiman (2002) também propõe que as práticas orais sejam analisadas em eventos de letramento. Para essa autora, a inserção do aluno nas práticas sociais de uso da escrita sustenta-se na oralidade letrada do professor. Dessa forma, segundo ela, o trabalho com a linguagem na escola deve privilegiar a leitura e a discussão sobre as várias possibilidades de ler, falar e de escrever um texto, dependendo do contexto, do objetivo do texto e de quem vai recebê-lo.

Por sua vez, Mortimer, Vieira e Araújo (2010) afirmam que o aprendizado nas aulas de ciências depende do diálogo estabelecido entre a linguagem científica escolar e a linguagem cotidiana. Em suas investigações, eles lançam mão da teoria dos gêneros de discurso e gêneros textuais para a compreensão dos textos produzidos pelos alunos. De acordo com esses autores, a aprendizagem das ciências depende de um processo em que os alunos vão construindo habilidades no uso de diferentes gêneros da ciência escolar. Essa construção passa necessariamente pela leitura e escrita dos diversos gêneros e tipos de textos.

\section{Metodologia}

A produção oral das crianças nas aulas de ciências com base na leitura da revista CHC é o principal objeto desta reflexão. Assim, antes de apresentar os procedimentos que levaram a cabo este estudo, é importante apresentar e analisar sumariamente a revista $\mathrm{CHC}$, objeto de leitura privilegiado em nossa investigação. Além disso, o destaque para a CHC se justifica porque esse periódico é enviado pelo Ministério da Educação (MEC) para as escolas públicas brasileiras, mas é pouco conhecido pelas crianças e professoras das séries iniciais e ainda pouco 
analisado em pesquisas acadêmicas. Assim, optamos por evidenciar aspectos relevantes que diferenciam esse material de outros do mercado brasileiro que veiculam textos de divulgação científica para crianças. Isso posto, segue uma breve apresentação da revista.

\section{A revista Ciência Hoje das Crianças}

Criada em 1986, Ciência Hoje das Crianças (CHC) é a revista de divulgação científıca para crianças da Sociedade Brasileira para o Progresso da Ciência (SBPC). A revista tem caráter multidisciplinar e publica, sob as formas mais variadas, temas relativos às ciências humanas, exatas e biológicas, às geociências, ao meio ambiente, à saúde, às tecnologias e à cultura. Seu objetivo é promover a aproximação entre cientistas, pesquisadores e público infantil em geral, incentivando o fazer e o saber científicos e estimulando a curiosidade das crianças para fatos e métodos das ciências. Além disso, ela propõe-se a divulgar aspectos da cultura brasileira, possibilitando a ampliação do universo cultural das crianças.

A CHC tem como público-alvo crianças entre 7 e 14 anos. Com pauta diversificada, a revista tem múltipla utilização: para as crianças, como material de leitura e apoio à pesquisa escolar; para os professores, como alternativa ao material estritamente didático; para as bibliotecas, como fonte permanente de consulta. Todas as matérias científicas são produzidas por pesquisadores e professores da comunidade científica brasileira e versam sobre objetos e métodos de pesquisa atualmente investigados. A publicação recebe tratamento gráfico e editorial cuidadoso e diversificado, o que lhe confere uma de suas principais características: a agilidade de linguagem escrita e visual.

A CHC é composta basicamente por três artigos grandes - sobre diferentes temas das ciências -, experiências, jogos, contos, resenhas (de livros, discos, filmes, peças de teatro, televisão, brinquedos), cartaz - patrimônio natural, cultural e histórico - e uma seção de cartas que incorpora à publicação as contribuições do público. Os artigos científicos da CHC, enviados espontaneamente ou encomendados pela equipe, recebem tratamento jornalístico, mas sempre são assinados por pesquisadores, fonte daquela informação.

A CHC surgiu como encarte da revista Ciência Hoje dos adultos e, ao longo de sua história, foi se inserindo nas escolas e adquirindo caráter paradidático, não proposto inicialmente. Atualmente, mais de $60 \mathrm{mil}$ escolas públicas do Brasil recebem a revista em suas bibliotecas. A revista tem uma tiragem de 340 mil exemplares por mês. Dessa parcela, apenas 10\% é de assinantes. Em uma palestra proferida na Universidade Federal de Ouro Preto, no dia 21 de junho de 2011, Bianca Encarnação, editora executiva da CHC, ressaltou que o conteúdo da revista sofre influência dos Parâmetros Curriculares Nacionais e, por essa razão, é comprada pelo Ministério da Educação. Quanto à leitura da CHC no ambiente escolar, Bianca Encarnação salientou sua preocupação em relação ao acesso à revista pelas crianças de escolas públicas. A editora considera importante o papel do professor em garantir o acesso das crianças à revista e aos textos de divulgação científica em geral para democratizar a ciência. Foi a partir de posicionamentos como esse que investimos em pesquisas sobre a divulgação científica para crianças e encontramos, nesse percurso, um campo de estudos ainda pouco explorado, o que reafirma a importância desse material para o desenvolvimento do letramento nas aulas de ciências das séries iniciais.

\section{O caminho escolhido para a compreensão das retextualizações na sala de aula}

Com o objetivo de analisar as interações e práticas de letramento mediadas pela revista CHC na sala de aula, foram registradas cenas de trabalho em aulas de ciências, com crianças na faixa etária entre 9 e 10 anos $-4^{\circ}$ ano do Ensino 
Fundamental - de uma escola pública da rede municipal da cidade de Belo Horizonte. A professora atuava nas séries iniciais há 20 anos e havia se formado em pedagogia há menos de 10 anos. A professora e todos os responsáveis pelas crianças assinaram um termo de consentimento livre e esclarecido para participar da pesquisa, no qual foram descritos os procedimentos de registro e a não identificação dos sujeitos de pesquisa quando da publicação dos resultados. No que concerne ao trabalho com esses eventos, optou-se pela análise microgenética (GÓES, 2000), dada sua vinculação com a matriz sociocultural, resultando num relato minucioso dos acontecimentos, conforme descrito a seguir. Os procedimentos metodológicos incluíram registros em vídeo, notas de campo e gravações em áudio de reuniões com a professora. 0 evento extraído dessa aula compõe parte dos dados da tese de Almeida (2011).

Durante três meses, acompanhamos as aulas de ciências em uma das turmas em que a professora atuava, e o acervo da pesquisa corresponde a 18 horas de filmagem ordenadas por data, um caderno de campo, entrevistas gravadas e transcritas e documentos normativos da escola. Com efeito, foi possivel construir um cronograma fixo para as filmagens: na última aula das terças-feiras e nos dois primeiros horários das quintas-feiras. Após cada filmagem, seguiam-se os seguintes procedimentos: assistir às fitas repetidas vezes, com o objetivo de representar as interações das crianças e da professora com a $\mathrm{CHC}$, os padrões discursivos das aulas e a organização do trabalho com a revista. A partir desse minucioso exame das aulas, procedeu-se à construção de mapas que dimensionam em uma tabela as ações mediadas pelo discurso dos participantes, as formas de uso da revista, o tempo transcorrido e as observações de campo.

Os mapas de ações apontam que, na primeira aula em que a revista $\mathrm{CHC}$ foi apresentada às crianças, a professora trabalhou a capa e o índice da revista. Ao fim dessa aula, ela distribuiu às crianças alguns exemplares para que lessem em casa. Na aula subsequente, segunda aula de que o episódio selecionado foi extraído, a professora indagou às crianças sobre a experiência de leitura da revista $\mathrm{CHC}$ no ambiente doméstico. Diferentemente da primeira aula, em que as crianças pouco participaram, nessa segunda aula, muitas crianças levantaram a mão, pedindo autorização para partilhar suas leituras. Assim, a escolha desse episódio se justifica por considerarmos que nele ocorrem eventos-chave que apontam para indícios de apropriação da revista e de formas de dizer a leitura de um texto de divulgação científica na sala de aula. Nesse dia, o desafio das crianças consistia em falar sobre o texto a partir das compreensões por elas construídas.

\section{Resultados e discussão}

Na manhã do segundo dia de trabalho com as revistas, a aula de ciências era a última do horário. Ao sinal para a troca de professores, as crianças guardaram na pasta os cadernos da aula de português e colocaram sobre as carteiras os cadernos de ciências e as revistas CHC. Quando entrou na sala, a professora cumprimentou as crianças com afeição e ocupou o mesmo lugar, à frente da turma, para falar aos alunos. Depois de chamar a atenção para o "tempo curto da aula", quis saber das crianças sobre a experiência de leitura da revista no ambiente doméstico. Muitas sinalizaram, com gritos e dedos em riste, o desejo de falar. Então, a professora solicitou que abrissem as revistas e comentassem "com as próprias palavras" o que haviam encontrado de mais interessante na CHC. Eram muitas as crianças que queriam partilhar suas leituras. Em meio a essas vozes, temas diversos tratados pela revista surgiram nos relatos de leitura. Em silêncio, com uma postura corporal ereta, algumas crianças buscaram a voz e o olhar do relator.

A seguir, apresentamos parte dessa aula dividida em duas sequências discursivas extraídas do primeiro evento de relatos de leitura de artigos da CHC pelas crianças na sala de aula. 
A transcrição é constituída de 37 turnos de fala. Desse total, 14 correspondem a intervenções da professora com o objetivo de distribuir as falas e 23 correspondem a intervenções dos alunos. $\mathrm{Na}$ primeira sequência, turnos de 1 a 24, evidenciamos as crianças relatarem suas leituras em um tom mais informativo, embora em alguns turnos apareçam marcas do discurso narrativo. Nessa primeira sequência, as reformulações são mais condensadas, com poucos casos de substituição ou acréscimo de palavras do repertório das crianças. A maioria das retextualizações dessa sequência é tão condensada que transforma o texto numa estrutura nominalizada. A informação é anunciada pelas crianças de uma maneira mais pragmática e mais próxima ao texto escrito, apesar de também aparecer nessa sequência o caráter colaborativo do discurso das crianças. 0 tipo de texto de divulgação científica escolhido pelas crianças e a forma de apresentação fazem da linguagem um ato expositivo. Vejamos, então, a primeira sequência:

Quadro 1 - Episódio 2: primeiro evento de relatos de leitura, sequência 1, retextualizações informativas

\begin{tabular}{|c|c|c|c|}
\hline $\mathrm{T}$ & Participantes & Discurso & Comentários \\
\hline 1 & Professora & Felipe & Aponta para um aluno. \\
\hline 2 & Felipe & $\begin{array}{l}\text { eu li o texto e o título é a linguagem dos códigos [...] o código é uma substituição de palavras por } \\
\text { signos [...] o código começou [...] é uma substituição de palavras por signos o código começou } \\
\text { quando um rei [...] ele queria esconder um tesouro, aí ele trocou o mapa por uns códigos porque se } \\
\text { alguém achasse o mapa ninguém ia entender [...] daí surgiu os códigos [...] depois, depois que eu } \\
\text { lembro veio o código Morse que era os códigos que [...] com as mãos }\end{array}$ & $\begin{array}{l}\text { Alunos olham atentamente } \\
\text { para o relator. }\end{array}$ \\
\hline 3 & Professora & $\begin{array}{l}\text { muito bem, tá vendo? a pessoa tem uma máquina que faz um barulhinho, cada barulhinho } \\
\text { corresponde a uma letra [...] porque aí a pessoa de muito longe consegue escrever uma } \\
\text { mensagem, ela consegue pelo número de toques, de barulhinho [...] uma outra pessoa que já } \\
\text { está treinada em ler esses códigos consegue ler os sinais [...] pelo toque ele vai saber qual letra, } \\
\text { né? mais alguém gostaria de falar? }\end{array}$ & $\begin{array}{l}\text { Movimento com os dedos } \\
\text { no ar. }\end{array}$ \\
\hline 4 & Alunos & EU, eu, EU, eu [...] & \\
\hline 5 & Professora & Lívia & Professora indica uma aluna. \\
\hline 6 & Lívia & $\begin{array}{l}\text { é que geralmente [...] tem uma pessoa assim, que a gente não vê todo dia ela fala: nossa, como } \\
\text { você cresceu, outro dia mesmo você era um bebê [...] lembra de quando você começou a falar? } \\
\text { falava tudo aos pedacinhos/ }\end{array}$ & $\begin{array}{l}\text { Aluna refere-se ao artigo "Do } \\
\text { blá-blá-blá ao be-á-ba". }\end{array}$ \\
\hline 7 & Tereza & o Diogo quer falar & $\begin{array}{l}\text { Aluno levanta o braço e uma } \\
\text { criança indica o colega. }\end{array}$ \\
\hline 8 & Professora & pode dizer Diogo & \\
\hline 9 & Diogo & $\begin{array}{l}\text { eu li o texto [...] por que chove granizo? [...] porque às vezes as nuvens estão altas e as gotas } \\
\text { de água descem e a temperatura é tão alta que gela [...] mais ou menos a sessenta ou setenta } \\
\text { abaixo de zero e que [...] e vira camada de gelo aí que/ }\end{array}$ & \\
\hline 10 & Tito & e cai na Terra/ & \\
\hline 11 & Tomas & e cai na Terra parecendo cubo de gelo/ & \\
\hline 12 & Professora & legal! tem mais alguém? Inácio quer falar também? então pode falar pra nós [...]/ & Aluno levanta o dedo. \\
\hline 13 & Nina & professora eu não ganhei a revista/ & \\
\hline 14 & Inácio & $\begin{array}{l}\text { é que [...] existem estrelas e planetas além desses que giram em torno do nosso sistema solar } \\
{[\ldots . .] \text { aqui diz que tem planetas que rodam em torno das estrelas [...] }}\end{array}$ & \\
\hline 15 & Professora & $\begin{array}{l}\text { e você? você também leu? você quer falar também? então fala bem alto para os seus colegas } \\
\text { ouvirem }\end{array}$ & $\begin{array}{l}\text { Aponta para uma criança que } \\
\text { estava com o dedo levantado. }\end{array}$ \\
\hline 16 & Estela & $\begin{array}{l}\text { eu li sobre o curioso mundo das bactérias [...] os cientistas hoje acreditam que elas são seres } \\
\text { que existem na terra há mais de três milhões de anos/ }\end{array}$ & \\
\hline 17 & Professora & os cientistas dizem que são seres que existem há mais de TRÊS MILHÕES de anos, não é isso?/ & \\
\hline 18 & Armando & nossa senhora!! mais velho que a minha avó, que a minha bisavó/ & \\
\hline 19 & Professora & e você acha que isso é ciência? & \\
\hline 20 & Helena & EU ACHO! & \\
\hline 21 & Professora & é ciência, né gente? agora o José [...] & \\
\hline 22 & José & $\begin{array}{l}\text { eu li com o meu primo essa aqui ó [...] ele constrói sua própria casa com pedras e flores e faz } \\
\text { sua saliva como [...]/ }\end{array}$ & Aponta para 0 artigo. \\
\hline 23 & Sofia & cola [...] ele usa água da saliva e oxigênio & \\
\hline 24 & Alunos & {$[\ldots] /$} & Incompreensível. \\
\hline
\end{tabular}


Depois de receber autorização para falar, um aluno, no turno 2, conta sua experiência de leitura sobre o código Morse, o que podemos analisar como uma ação de retextualizar. Ele apresenta formalmente o texto, destacando, em primeiro lugar, o título do artigo lido, como uma estratégia que envolve a compreensão de como se deve anunciar um texto informativo e iniciar a apresentação na sala de aula. Em seguida, ele se concentra na explicação do que seria o código Morse e na história da invenção dos códigos. 0 dizer "que eu lembro" permite indiciar uma percepção em torno do nível de informação do texto, especialmente em relação à falta, à informação ausente - um fator que se concretiza para a criança, de modo mais claro, durante o processo de apropriação do texto. 0 aluno tem consciência de que outras informações existem no texto e não são ditas por ele, e por isso seleciona intencionalmente partes que julga mais importantes para si e para seus endereçados. Ainda no turno 2, o aluno, ao mesmo tempo em que cita o discurso do outro "eu li o texto"-, assume-se como sujeito de seu discurso, misturando formalidade e aproximação com o discurso cotidiano. No discurso desse aluno, também se percebe um apagamento do sujeito, o que gera um discurso indireto e, ao mesmo tempo, uma costura narrativa, presente no texto escrito e no oral, envolvendo o leitor e o ouvinte.

No turno 3, o feedback da professora é avaliativo, com a função de confirmar a resposta e redimensionar o discurso. Sua audiência são os alunos e seu propósito é ensinar a ideia de código por meio da retextualização realizada pelo aluno. 0 convite da professora tem o caráter mais de persuasão do que de imposição.

Já o turno 4 caracteriza-se pelo entusiasmo das crianças e pelo desejo de falar sobre o texto lido. E os turnos 6 e 22 caracterizam-se pelo comprometimento na compreensão do artigo. A retextualização, nesses turnos, reduz tão exageradamente as informações que é difícil ao ouvinte entender o discurso. Ora, se o traço principal do gênero de divulgação científica é a informação, é necessário que nos discursos orais ela apareça nítida. No entanto, o que se vê nesses turnos é um apagamento da informação, acarretando comprometimento na compreensão do texto.

No turno 9, um aluno retextualiza o texto da revista com o propósito de explicar a chuva de granizo. A maioria dos termos por ele empregados coincide com os utilizados no artigo, porém podem não compartilhar o mesmo significado. A informação foi tão reduzida pela criança que não há garantias de compreensão do conteúdo do texto.

No turno 13, uma aluna reclama a falta da revista. Esse é um indício importante do valor que a $\mathrm{CHC}$ passou a ter para as crianças. Aliás, durante a pesquisa de campo, elas nunca reclamaram da falta dos textos fotocopiados que não receberam, mas, no caso das revistas, todos cobravam da professora o número que não receberam quando faltavam à aula.

No turno 16, uma aluna também anuncia o texto com o título e, além disso, recorre à voz dos cientistas para a construção de sua fala - "são eles que dizem, eles acreditam”. Dessa maneira, na construção de um discurso indireto, as crianças iam se tornando autoras de seu próprio discurso. Esse trabalho de compreensão dos artigos denota a diferença de investimento, por parte da criança, entre a narrativa do vivido e a retextualização de um texto informativo. No relato do texto informativo, o vivido é evitado, deslocando a ênfase para a voz de autoridade do texto - o cientista -, o outro que fala.

No entanto, no turno 18, esse vivido aparece em uma situação que mostra a importância da relação dialógica no trabalho com a leitura nas aulas de ciências. A criança compara o tempo de vida das bactérias na Terra ao tempo das avós. Ainda que a dimensão do tempo seja difícil para a compreensão desse aluno, ao ouvir a informação, ele compara e internaliza as ideias e, nesse processo, vai elaborando uma forma de diálogo do vivido com as questões relativas à ciência do texto oral e escrito. 0 que detectamos aqui é outra 
dimensão da substituição do texto escrito pelo texto oral no processo de retextualização que envolve a percepção ontológica de tempo. Essa sequência discursiva destaca o cruzamento dialógico e ontológico na elaboração de sentidos, na qual alunos e professora alternam suas posições para concluírem que, afinal, "isso é ciências”. Assim, no turno 21, a professora legitima o discurso da revista ao ressaltar que as informações apresentadas pertencem ao campo das ciências.

De modo geral, no decorrer desse episódio, os conhecimentos são partilhados por crianças que leram o mesmo artigo. Isso pode ser observado, por exemplo, no turno 23, quando uma aluna auxilia o colega na explicação do artigo. Esse fator é considerado de grande relevância para esta investigação, uma vez que, nessa dinâmica discursiva, ficam explicitados os movimentos e recursos constitutivos do processo de construção coletiva do conhecimento na sala de aula.

Na sequência 2 - turnos de 25 a 37 -, a dinâmica discursiva mantém o caráter colaborativo, mas aparece em alguns turnos de fala um discurso narrativo, menos pragmático que o da primeira sequência. 0 discurso na sequência 2 não é apenas um ato expositivo. Os fatos são apresentados numa ordem sequencial que vai persuadindo o leitor, pois o argumento presente no artigo aparece na oralidade de maneira convincente, como uma extensão do discurso canônico. Nesse caso, há uma expansão do discurso e reformulações cujo objetivo é explicitar e realçar o artigo lido. Tendo em vista essas questões, alguns turnos da sequência 2 foram escolhidos como fonte para análise de retextualizações. Vejamos, então, a segunda sequência.

Quadro 2 - Episódio 2: primeiro evento dos relatos de leitura, sequência 2, retextualizações narrativas

\begin{tabular}{|c|c|c|c|}
\hline $\mathrm{T}$ & Participantes & Discurso & Comentários \\
\hline 25 & Professora & vamos ouvir a Lourdes... ela quer fazer um comentário sobre o que ela leu & \\
\hline 26 & Lourdes & $\begin{array}{l}\text { é [...] eu li que uma pesca lá dos golfinhos com os seres humanos [...] que } \\
\text { os golfinhos [...] eles ajudam os pescadores a pescar porque quando eles } \\
\text { [...] é [...] os golfinhos estão [...] acho que na beira da maré da praia eles } \\
\text { encurralam os peixes e os pescadores e jogam é [...] coisinhas lá neles/ }\end{array}$ & $\begin{array}{l}\text { Estudantes voltam a atenção para a } \\
\text { aluna e ficam em silêncio. }\end{array}$ \\
\hline 27 & Catarina & a rede/ & \\
\hline 28 & Lourdes & $\begin{array}{l}\text { é [...] a rede e pescam os peixes e [...] e [...] eles [...] os golfinhos [...] } \\
\text { eles também gostam [...] eles são muito brincalhões porque eles não têm } \\
\text { medo de seres humanos, né? eles gostam de brincar nas ondas, gostam de } \\
\text { brincar [...] sabe umas plantas que ficam flutuando assim?/ }\end{array}$ & Faz gesto de onda com a mão. \\
\hline 29 & Professora & sei/ & \\
\hline 30 & Fátima & algas marinhas/ & \\
\hline 31 & Lourdes & $\begin{array}{l}\text { é [...] as algas marinhas [...] eles gostam de afundar aquelas coisinhas e } \\
{[\ldots] \text { e [...] aí também descobri que os PASSARINHOS NÃO TÊM DENTES! }} \\
{[\ldots . .]}\end{array}$ & $\begin{array}{l}\text { A aluna gesticula, ri, altera o tom de } \\
\text { voz e fala espantada sobre } 0 \text { artigo. }\end{array}$ \\
\hline 32 & Professora & $\begin{array}{l}\text { olha que interessante! conta para os seus colegas o que você descobriu } \\
\text { através do texto }\end{array}$ & \\
\hline 33 & Lourdes & $\begin{array}{l}\text { que os passarinhos, cada um, de acordo com a forma deles [...] eles é [...] } \\
\text { conseguem pegar a comida e cortar de um jeito... tipo os carnívoros com } \\
\text { seu bico mais afiado que consegue cortar a carne, tem uns pássaros que } \\
\text { têm um bico que eles tem [...] tipo [...] umas barras assim que... que.... } \\
\text { ajuda a prender o inseto/ }\end{array}$ & \\
\hline 34 & Professora & 0 inseto/ & \\
\hline 35 & Tito & quando ele vai comer $[\ldots]$ & \\
\hline 36 & Professora & interessante, né, gente? gostaram da descoberta dela através do texto? & \\
\hline 37 & Tito & anhan, anhan & \\
\hline
\end{tabular}


No turno 25, a professora, mais uma vez, intervém para distribuir a fala. No turno 26, uma aluna inicia a retextualização do artigo da CHC sobre os golfinhos e os alunos ficam em completo silêncio. Nesse turno, ao falar sobre o artigo, a aluna incorpora em seu discurso uma estrutura de sucessão em uma espécie de gramática narrativa dos acontecimentos entre golfinhos e seres humanos. E como também nesse turno há omissões de palavras do texto, outra aluna, no turno 27, a auxilia no relato. Assim, pode-se observar que a construção do texto oral ocorre entre os estudantes que se tornam referentes e andaimes na elaboração narrativa. Ao retextualizar, a aluna recorre ao discurso narrativo e explicativo, imprimindo um tratamento particular à informação. 0 uso de uma linguagem narrativa constitui formas de ordenar a memória e o conhecimento (BRUNER, 1997). Nessa sequência, ao narrar, a aluna imprime à informação um significado individual e o sentido que o evento tem para si, pelo uso explícito de avaliações e gestos. No turno 31, a criança altera o tom de voz ao informar, impressionada, que os pássaros não têm dentes. Essa explosão vocal é a dimensão emotiva do texto oral que não aparece no discurso escrito. A informação envolve tanto a aluna que vem acompanhada de movimentos corporais que ajudam a significar as palavras no processo de interação verbal. 0 artigo é muito curioso para a criança, e o envolvimento dela no conteúdo do texto é tão forte que ela ri, gesticula, balança o corpo e altera o tom de voz. Dessa forma, os outros ouvintes ficaram entusiasmados pelo artigo e presos na fala dessa aluna. A voz, assim, acompanha e apoia a organização e a complementação de sentidos constitutivos do discurso.

No turno 32, o convite da professora para que a aluna continue seu relato é uma estratégia didática que busca sustentar um tipo de interação que demanda a opinião ou interpretação da criança, conforme identificado por Mehan (1979) em seus estudos. A voz da professora aparece para colaborar ou orquestrar os discursos da sala de aula. A professora incentiva a criança a relatar sua leitura, referindo-se ao ato de ler o artigo como uma descoberta. Esse sentido que a professora encontra para a leitura leva a aluna à construção de um texto explicativo no turno 32 em que ela apresenta o tema - os tipos de bicos dos pássaros e suas funções - e o categoriza quando faz menção a diferentes formas de aves e bicos. 0 discurso expressa a compreensão das relações que ordenam o texto científico: forma (os diferentes bicos dos pássaros) e função (os pássaros têm bicos diferentes e apresentam características alimentares diferentes). Assim, na habilidade dessa aluna em retextualizar o artigo, é possível identificar a comparação, a seleção das informações, a ordenação e a categorização.

Outro aspecto observado nos relatos é que, ao retextualizar, a criança vai construindo uma espécie de revisão da própria fala. Assim, no turno 33, o discurso de uma aluna revela que o conceito expresso no texto vai sendo ampliado, reconstruído, englobando ideias cada vez mais sofisticadas acerca do assunto. A princípio, ela cita, de maneira generalizada, os passarinhos que, "de acordo com a forma deles, conseguem pegar a comida”. Mais adiante, cita os pássaros que, "com seu bico afiado, conseguem cortar a carne”. Esse processo de retificação e de retomada das ideias é fundamental nos textos oral e escrito, sendo constituinte do ato de revisar. 0 movimento de avanços e recuos assinala a possibilidade de o aprendiz lidar com o texto de sua autoria. Tal construção é um movimento de um sujeito que é capaz de pensar, com autonomia, a leitura que faz do texto, porque está se apropriando de mecanismos que permitem a (re)construção de um texto a partir da interação com ele.

Assim, expor um texto viabiliza a interação do leitor com o escritor, a explicitação das vozes do texto e o surgimento de um autor. Dessa forma, a retextualização constitui uma prática de letramento que concretiza, para o leitor, uma oportunidade 
de, ao dizer, ver o texto de outro lugar, ser autor de outro texto. Portanto, pode-se dizer que há um deslocamento do eu leitor para o eu autor em meio à substituição do texto escrito pelo oral, pois, ao apresentar o artigo, a criança constrói outra compreensão do texto, outro discurso - enfim, seu próprio discurso. Nesse episódio, a retextualização do gênero de divulgação científıca pode ser vista como uma ferramenta que atua diretamente no discurso.
Dada a extensa lista de retextualizações realizadas pelas crianças nessa aula, será analisado com mais profundidade apenas um caso comentado por uma aluna sobre o artigo Tem boto na pescaria. E não é na rede de pesca!, que faz parte do turno 26. 0 artigo a que se refere essa análise foi matéria de capa do número 146 da CHC, em maio de 2004, e ocupou cinco páginas da revista. 0 trecho original do artigo e a transformação realizada podem ser observados no quadro 3.

Quadro 3 - Retextualização do artigo da CHC Tem boto na pescaria..., turno 26

\begin{tabular}{|c|c|c|}
\hline Trecho do texto original da CHC & Retextualização & Linhas \\
\hline Os botos ajudam muito os pescadores a & é [...] eu li que uma pesca lá dos golfinhos & 1 \\
\hline achar peixes nas águas turvas da barra de & com os seres humanos [...] que os golfinhos... & 2 \\
\hline Tramandaí, pois, ao localizar um cardume, & eles ajudam os pescadores a pescar porque & 3 \\
\hline eles se comportam de forma especial: dão & quando eles [...] é [...] os golfinhos & 4 \\
\hline saltos, viram o corpo, batem com a cabeça & estão [...] acho que na beira da maré da praia & 5 \\
\hline na água... Além disso, para encurralar os & eles encurralam os peixes e os pescadores & 6 \\
\hline peixes e dificultar sua fuga, procuram & e jogam é [...] coisinhas lá neles & 7 \\
\hline levá-los até as margens, onde ficam os & [a rede] & 8 \\
\hline pescadores! Portanto, não é à toa que, ao & & 9 \\
\hline ver Barata e companhia na barra de & & 10 \\
\hline Tramandaí, os pescadores preparam suas & & 11 \\
\hline tarrafas - redes circulares arremessadas & & 12 \\
\hline abertas na água. Como sabem identificar 0 & & 13 \\
\hline comportamento que os botos apresentam & & 14 \\
\hline quando acham peixes e ainda têm a ajuda & & 15 \\
\hline deles para levar o cardume até a margem, & & 16 \\
\hline a pesca é certa! & & 17 \\
\hline
\end{tabular}

Na linha 1, observa-se que a aluna inicia seu discurso com a expressão "eu li”. Assim, já na primeira linha, ela faz referência ao artigo, deixando flagrante a preocupação em indicar o discurso do outro. Depois, o discurso aparece em $3^{a}$ pessoa, o que revela um apagamento do autor. Ainda na linha 1, ela usa a palavra "golfinho", apesar de o animal ser denominado boto em quase a totalidade do texto. Segundo Vigotski (1991), são as experiências cotidianas da criança com o uso da palavra que levam à generalização.

Nas linhas 1 e 2, a criança define a pesca cooperativa como a "pesca dos golfınhos lá com os seres humanos". Essas duas linhas demonstram a repetição e a compreensão do texto pela criança. Ela não usa as mesmas palavras do texto, mas repete as ideias. Esse movimento indica o trabalho de compreensão realizado pela criança. A palavra pescadores não aparece na linha 1; em vez disso, ela usa "seres humanos", o que parece indicar consciência da situação de produção do discurso - uma escola, uma aula de ciências, um texto de divulgação científica.

Já na linha 3, a aluna reformula sua fala, reportando-se ao discurso da CHC na linha 1: "eles [os golfinhos] ajudam os pescadores". 
Para Bakhtin (1981, p. 144), “o discurso citado é o discurso no discurso, a enunciação na enunciação, mas é, ao mesmo tempo, um discurso sobre o discurso, uma enunciação sobre a enunciação”. Marcuschi (2001a, p. 54) aponta, como uma das variáveis relevantes para a retextualização, a "relação entre o produtor do texto original e o transformador", dizendo que, quando é o próprio autor que retextualiza, as mudanças são muito mais radicais; já no caso de outra pessoa, ela fará menor número de mudanças no conteúdo, embora possa fazer muitas mudanças na forma. Em se tratando da retextualização de um texto de divulgação científica, cujo discurso é de autoridade e traz implícita a ideia de que, sob a presença de fatos, há que se construirem argumentos, o discurso tende a ser o mais próximo possível do discurso do artigo. No caso da aluna em questão, ela valoriza o conteúdo da mensagem de divulgação científica como ideal para ser transmitido. Desse modo, as linhas 3, 4 e 5 do artigo descrevem em detalhes o comportamento dos botos quando localizam um cardume.

A criança resume essa informação e preserva a fidelidade ao texto escrito ao usar a palavra "encurralar". A partir da linha 10, ela privilegia outro fragmento do artigo, citando características do comportamento dos golfinhos que, para ela, são mais significativas e passíveis de ser informadas. Dessa forma, essa aluna se apropria das formas do discurso de divulgação científica e, ao mesmo tempo, torna a linguagem próxima e também objetiva, eliminando, na retextualização, o nome do lugar, alguns detalhes do comportamento dos botos, nomes próprios e a explicação da palavra tarrafa. Tudo isso pode ser visto nas linhas de 5 a 9. A linha 8 mostra outras crianças acompanhando e entendendo a narrativa. Assim, a retextualização obriga a criança ao trabalho de metalinguagem, pois a leva a rever o texto, sua forma e seu conteúdo, e assim, afirma e amplia sua experiência discursiva, incluindo a experiência de tomar a própria linguagem - ou aspectos dela - como objeto.

\section{Considerações finais}

A análise desses fragmentos mostra que as crianças deixam transparecer, nas formas de falar, suas experiências com a revista CHC. Nesse processo, em que as crianças são instigadas a interpretar e produzir sentidos em torno do texto, gera-se um mecanismo no qual elas e também a professora vão se apropriando de certas formas de dizer o texto, caracterizando-se, portanto, como um exercício de metalinguagem. Nessa perspectiva, a retextualização constitui uma prática de letramento do contexto dessa sala de aula que imprime ao texto oral uma forma particular de falar sobre o texto. Tal exercício de metalinguagem é um trabalho de compreensão que cada criança produz ao tentar fazer com que seu dizer seja mais inteligível e próximo das explicações do artigo de divulgação científica. Afınal, é preciso dizer o texto e, para isso, é necessário fazê-lo de acordo com as convenções da aula, da audiência, do conteúdo do texto e de sua forma. Segundo Geraldi (2002), ao produzir um texto, o sujeito faz uma proposta de compreensão ao seu interlocutor, desenvolvendo ações com a linguagem e ações sobre a linguagem. Isso se realiza por meio de escolhas de estratégias para o dizer, o que envolve a atividade cognitiva.

Na medida em que essa forma de se referir ao texto exige compreensão e construção de significados, as consequências das retextualizações nas aulas de ciências são a possibilidade de expressão de conhecimentos, a construção de ideias e a habilidade de uso de uma linguagem explicativa. Trata-se de uma operação em que as crianças necessitam negociar os sentidos, contextualizar as informações, compartilhar conhecimentos e preencher as lacunas implícitas do texto, demonstrando um trabalho de compreensão da leitura dos artigos de divulgação científica. Assim, o dizer os textos de divulgação científica na sala de aula se constituiu como estratégia importante para a criança não apenas falar melhor sobre artigo, mas falar de outro jeito e compreender de outro modo os textos e a linguagem das aulas de ciências. 
Em alguns momentos, as exposições orais das crianças parecem constituir-se em monólogos. Em geral, não há perguntas nem longos comentários após os relatos. Contudo, percebe-se a atitude compreensiva e responsiva daquele que leu o mesmo texto e daquele que ficou na escuta. Os relatores interagem com a plateia por meio de expressões como: eu li sobre, depois, que eu lembro, a gente, aqui diz. Essas expressões dão significado ao texto por um viés envolvente. Ao manter o silêncio e apresentar disposição para ouvir, apreciar os textos dos colegas, acrescentar e concordar, a turma desempenha um papel importante na organização discursiva da exposição, como também observa Bovet (1999 apud ROJO; SCHNEUWLY, 2006).

Os relatos de leitura proporcionaram às crianças um modo de participação que lhes permite construir relações com os textos de divulgação científıca, ora como prática discursiva, ora como objeto de referência. De acordo com Vigotski (1991), a fala da criança: organiza seu pensamento, ou seja, à medida que se expressa oralmente, ela elabora os acontecimentos; estrutura início, meio e fim; percebe e preenche lacunas; estende e amplia seu discurso. Ao retextualizar, as crianças usam palavras de seu repertório ao mesmo tempo em que novas palavras são inseridas no discurso, concretizando-se, assim, o diálogo com o texto de divulgação científica.

Outro aspecto importante a ser observado nesse episódio é que as crianças só se referem aos textos de ciências. Isso provavelmente decorre do fato de que, na primeira aula, elas foram apresentadas à $\mathrm{CHC}$, ouviram a professora comentar algumas características do suporte e enfatizar a leitura de uma revista científica. Infere-se desse procedimento, pois, a existência de um processo anterior à leitura da revista pelo qual os alunos são orientados para a seleção dos textos a serem relatados, do conteúdo da aula, do que pode e deve ser dito. Isso indicia escolhas relacionadas aos efeitos de sentidos previstos para aquela situação comunicativa.
Em última análise, a liberdade para apresentar suas leituras e a ausência de controle sobre o conteúdo do texto são aspectos que afastam essa prática da tradição escolar, tornando os momentos dos relatos peculiares. No entanto, há um antagonismo nessa prática que gera tensões. Por um lado, a professora possibilitava que as crianças falassem de suas aprendizagens realizadas com a leitura da CHC; por outro, o objetivo do relato se baseava na necessidade da professora em saber se as crianças haviam lido, o que leram e o que haviam aprendido com a leitura. Em sala de aula, tradicionalmente, as crianças aprendem com a professora, mas, no caso dos relatos, essa relação se modificou, porque as crianças tinham o domínio de certas informações que a professora não controlava. A forma de organização da atividade em torno de uma ferramenta cultural pouco difundida na sala de aula - a revista de divulgação científica em suporte original - e a disposição da professora por interações simétricas com menor controle temático dos enunciados dos alunos resultaram em retextualizações com evidências sobre a compreensão dos textos de divulgação científica, seja por suas características informativas, seja por sua natureza narrativa.

Essa postura da professora se coaduna com uma prática de introduzir o ensino de ciências por meio de relações que, se não espelham, mantêm importantes aproximações com certas formas de produção de conhecimento na área. Assim, além do enfoque temático propiciado por essa prática relativamente inusitada nas aulas de ciências, destaca-se que a aquisição da língua ocorre em meio a um processo que permite o revozeamento daquele que pratica a ciência e, nesse sentido, veicula novas formas de pensar para o aluno. Essa é uma importante característica dos textos de divulgação científica que certamente deve ser considerada nas fases iniciais de letramento escolar. 


\section{Referências}

ALMEIDA, Maria José P. M. de. 0 texto de divulgação científica como recurso didático na mediação do discurso escolar relativo à ciência. In: PINTO, Gisnaldo A. (Org.). Divulgação científica e práticas educativas. Curitiba: CRV, 2010.

ALMEIDA, Sheila Alves de. Ver o invisível: as metamorfoses do aprender e do ensinar ciências em uma experiência de professoras do primeiro ciclo. Dissertação (Mestrado) - Universidade Federal de Minas Gerais, Belo Horizonte, 2005.

ALMEIDA, Sheila Alves de. Interações e práticas de letramento mediadas pela revista Ciência Hoje das Crianças. Tese (Doutorado) - Universidade de São Paulo, São Paulo, 2011.

ALMEIDA, Sheila Alves de; GIORDAN, Marcelo. Discursos que circulam na correção de um questionário: sentidos e significados. Ensaio: Pesquisa em Educação em Ciências, Belo Horizonte, v.14, n. 3, p. 239-259, 2012.

BAKHTIN, Mikhail. Marxismo e filosofia da linguagem. 8. ed. São Paulo: Hucitec, 1981.

BAKHTIN, Mikhail. Estética da criação verbal. 3. ed. São Paulo: Martins Fontes, 1997.

BRUNER, Jerome. Atos de significação. Porto Alegre: Artes Médicas, 1997.

BUNZEN, Clecio dos Santos. Dinâmicas discursivas na aula de português: os usos do livro didático e os projetos didáticos autorais. Tese (Doutorado) - Universidade Estadual de Campinas, Campinas, 2009.

CASSIANI, Suzani. Condições de produção de sentidos em textos didáticos. Ensaio: Pesquisa em Educação em Ciências, Belo Horizonte, v. 8, n. 1, jul. 2006.

COLELLO, Silvia. Alfabetização e letramento: repensando o ensino da língua escrita. Videtur, Porto, n. 29, 2004. Disponível em: <http://www.hottopos.com/videtur29/silvia.htm>. Acesso em: mar. 2013.

ESPINOZA, Ana. Ciências na escola: novas perspectivas para a formação dos alunos. São Paulo: Paidós, 2010.

ESPINOZA, Ana; CASAMAJOR, Adriana; PITTON, Egle. Enseñar a leer textos de ciências. Buenos Aires: Paidós, 2009.

GERALDI, João Wanderley (Org.). 0 texto na sala de aula. 3. ed. São Paulo: Ática, 2002.

GÓES, Maria Cecília Rafael de. A abordagem microgenética na matriz histórico-cultural: uma perspectiva para 0 estudo da constituição da subjetividade. Cadernos CEDES, Campinas, ano 20, n. 50, p. 9-25, 2000.

GOULART, Cecília. Letramento e modos de ser letrado: discutindo a base teórico-metodológica de um estudo. Revista Brasileira de Educação, Campinas, v. 11, n. 33, p. 450-562, set./dez. 2006.

GOUVÊA, Guaracira. A divulgação científica para crianças: 0 caso da Ciência Hoje das Crianças. Tese (Doutorado) - Universidade Federal do Rio de Janeiro, Rio de Janeiro, 2000.

KLEIMAN, Ângela. Oralidade letrada e competência comunicativa: implicações para a construção da escrita em sala de aula. Scripta, Belo Horizonte, v. 6, n. 11, 2002.

KLEIMAN, Ângela. Leitura: ensino e pesquisa. Campinas: Pontes, 2004.

MARCUSCHI, Luiz Antonio. Da fala para a escrita: atividades de retextualização. 2. ed. São Paulo: Cortez, 2001a.

MARCUSCHI, Luiz Antonio. Letramento e oralidade no contexto das práticas sociais e eventos comunicativos. In: SIGNORINI, Inês (Org.). Investigando a relação oral/escrito. Campinas: Mercado de Letras, 2001b.

MARINHO, Marildes. As condições de existência do texto escolar. Viva Voz Cadernos, Belo Horizonte, v. 3, p. 33-45, 1993.

MASSARANI, Luisa. La divulgación científica para niños. Quark: periodismo científico en un mundo diverso, n. 34, out./dez. 2007. 
Disponível em: <http://www.prbb.org/quark/17/017040.htm>. Acesso em: mar. 2013.

MEHAN, Hugh. Learning lessons: social organization in the classroom. Cambridge: Harvard Press, 1979.

MORTIMER, Eduardo; VIEIRA, Ana Clara; ARAÚJO, Angélica Oliveira de. Letramento científico em aulas de química In: MARINHO Marildes; CARVALHO, Gilcinei T. (Orgs.). Cultura escrita e letramento. Belo Horizonte: UFMG, 2010. p. 336-362.

PAULA, Helder Figueiredo; LIMA, Maria Emília C. C. A leitura de textos didáticos de ciências como confronto de perspectivas. Revista Ensaio, Belo Horizonte, v. 13, n. 3, p. 185-205, 2011.

R0J0, Roxane (Org.). Gêneros orais e escritos na escola/tradução e organização. Campinas: Mercado de Letras, 2004.

ROJO, Roxane; SCHNEUWLY, Bernard. As relações oral/escrita nos gêneros orais formais e públicos: 0 caso da conferência acadêmica. Linguagem em (Dis)curso, Tubarão, v. 6, n. 3, p. 463-493, set./dez. 2006.

SILVA, Ezequiel Theodoro. Concepções de leitura e suas consequências no ensino. Perspectiva, Florianópolis, v. 17, n. 31, p. 11-19, jan./jun. 1999.

SOARES, Magda. Letramento: um tema em três gêneros. Belo Horizonte: Autêntica, 1998.

SOLÉ, Isabel. Ler, leitura, compreensão: sempre falamos da mesma coisa? In: TEBEROSKY, Ana et al. Compreensão de leitura: a língua como procedimento. Porto Alegre: Artmed, 2003.

SUTTON, Clive. Los professores de ciencias como professores de lenguaje. Enseñanza de las Ciências, v. 21, n. 1, p. 21-25, 2003.

VIGOTSKI, Lev S. Pensamento e linguagem. 3. ed. São Paulo: Martins Fontes, 1991.

ZILBERMAN, Regina. A leitura na escola. In: ZILBERMAN, Regina. (Org). Leitura em crise na escola: as alternativas do professor. Porto Alegre: Mercado Aberto, 1982.

ZIMMERMANN, Narjara; SILVA, Henrique César da. Condições de produção do imaginário sobre leitura da ciência de professores do ensino médio. In: ENCONTRO NACIONAL DE PESQUISA EM EDUCAÇÃO EM CIÊNCIAS, 6; 2007. Atas... Florianópolis: Abrapec, 2007.

Recebido em: 08.12.2012.

Aprovado em: 27.06.2013.

Sheila Alves de Almeida é doutora em Educação pela Universidade de São Paulo (USP) e professora do Departamento de Biodiversidade, Evolução e Meio Ambiente da Universidade Federal de Ouro Preto (UFOP).

Marcelo Giordan é doutor em Ciências pelo Instituto de Química da Universidade Estadual de Campinas (Unicamp), livre-docente pela Faculdade de Educação da Universidade de São Paulo (USP) e professor do Departamento de Metodologia de Ensino dessa mesma Faculdade. 